conditions. Equally there is an excellent balance between what may be called the clinical and physiological aspects of the subject. Hitherto anyone interested in this relatively new branch of surgery has had to seek information from a variety of sources. This authoritative text fills a real gap in British surgical literature and will be of value to all surgeons interested in this field. This book is written primarily for the postgraduate student, to whom it will undoubtedly be of the greatest value, both as a textbook for close study and as a work of reference. At the same time it can be recommended to the keen undergraduate student interested in this fascinating and growing aspect of surgery.

In a book covering such a wide field it is inevitable that some subjects should receive special attention, no doubt reflecting the main interests of the authors. Thus the chapters on the adrenal and thyroid glands are outstanding and there is an excellent chapter, written by Dr. Mary McGeown, on the parathyroid glands. In contrast some of the subjects, such as the surgical complications of diabetes and the concept of 'adrenal exhaustion', receive perhaps rather too brief attention in a book written for surgeons. However, such slight discrepancies are inevitable in a book which covers such a wide subject so comprehensively, and this minor criticism in no way detracts from an outstanding book.

\section{Iron Metabolism}

Thomas H. Bothwell and Clement A. Finch. Pp. 440, illustrated. London: J. \& A. Churchill. 1963. £5 7s. $6 \mathrm{~d}$.

This excellent monograph on iron metabolism is written by two practising physicians who have been interested in disorders of iron metabolism for a number of years and who have made many original contributions to the subject. The early chapters on iron absorption and turnover in the body and the regulation of plasma iron balance bring together information from many different sources. The description of techniques is full and the critical analysis of currently available methods used, for instance, in the measurement of serum iron level are particularly valuable. The accounts of isotope studies will be of considerable help to those concerned in the setting up of such techniques. Calculations are given of the actual dose of radiation received by the patient in the course of these investigations. The various clinical syndromes of iron deficiency and iron overload are considered in detail and the bibliography is extensive. Perhaps one is slightly disappointed that the several important gaps in our knowledge of idiopathic hæmochromatosis are rather glossed over and that the description of the role of environmental factors in the ætiology of the disease is superficial. These are small criticisms, however, of a book which will be of value to the general physician and pathologist as well as to the expert in the field.

\section{Compendium of Emergencies}

Editor: H. Gardiner-Hill, M.D., F.R.C.P. Pp. xi + 328. London: Butterworth. I963. $55 s$.

This compendium of emergencies is written by a score of specialists, each treating those emergencies most likely to occur in his field. The emergency is considered under three main headings-the nature and pathology of the condition, its recognition, and advice on its management and treatment, both initially and in hospital. The full value of each contribution can onl be assessed in the course of time by its practical help tळ the clinician suddenly confronted with a situation out side his normal scope and experience. Thus, it is the type of book which should be at hand on a nearby shelf or in one's cabin in a ship at sea.

The emergencies described are those usually seer and dealt with by Casualty officers or by the registrars? of the specialists writing this book. It is possible tha? their active co-authorship would have modernised certain sections; a subsequent edition must take int account the new semi-synthetic penicillins, intravenous pitressioi for bleeding œsophegeal varices, and mor£ adequate accounts of acute renal failure and hepatios coma. The treatment of poisoning is so important that? it needs to be enlarged. An outline of the new Mentab Health Act and the methods of compulsory admissionwould be valuable in the chapter on psychiatry. Th山् chapter on neurological emergencies is particularly clear, concise and helpful, and it could well be adopteg as a model for other chapters in another edition.

\section{The Abdominal Compression Reaction: Activity of Abdominal Muscles Elicited From the Circulatory System}

W. B. Youmans, Q. R. Murphy, J. K. Turnere L. D. Davis, D. I. Briggs and A. S. Hoye. Pp. $7 \varnothing$ with 45 figures. Baltimore: Williams and Wilkins? 1963. $32 s$.

This monograph presents material originally published in the American Journal of Physical Medicine The studies described are the alterations in activity o abdominal muscles and other skeletal muscles elicited by changes in the cardiovascular system. These studes indicate that the activity of the abdominal muscles is increased selectively as a reflex mechanism when the volume of blood in certain 'low pressure' portions the cardio-vascular system, most probably the $\overrightarrow{\text { leff }}$ atrium, is reduced. The rôle of the abdominal compres sion reflex apparently is to modulate cardiac filling్ without simultaneously producing considerable altera tions in tidal volume.

\section{Diseases of the Alimentary Tract}

Clifford F. Hawkins, M.D., F.R.C.P. Pp. 4 I 1 with 60 illustrations and six tables. Londono William Heinemann Medical Books. 1963. 6os.

This new book, though small in size, is very meat and a fitting testimony to the many significant con:tributions from Birmingham, especially, of course those relating to small gut function. Gastroenterolog is becoming an increasingly important and broaळ specialty and the consequent large volume of new? material has been well sifted and presented, making thio volume very up to date. It is definitely aimed at the open-minded postgraduate with emphasis on fact 8 rather than theory, as exampled by the way in whicl. medical therapy of peptic ulceration is dealt with in four succinct sides. One particularly helpful chapter is thaser in which a working account is given of a disparate group of common problems, which in other books tend to bev glossed over or omitted. The direct style has great appeal.

The layout and print are clear and pleasing, excepł for the half-width captions under the illustrations $\mathrm{X}$-ray reproductions are plentiful and excellent. Af extensive bibliography appears at the end. 